\title{
Metal-Organic Framework Synthesis System Based on Fuzzy Predictive Control via Network Transmission
}

\author{
Jui-Ho Chen and Hsi-Chun Wang \\ Department of Electrical Engineering, National Chin-Yi University of Technology, No. 57, Section 2, Zhongshan Road, \\ Taiping District, Taichung 41170, Taiwan \\ Correspondence should be addressed to Jui-Ho Chen; chenjh@ncut.edu.tw
}

Received 30 March 2014; Accepted 24 April 2014; Published 17 June 2014

Academic Editor: Her-Terng Yau

Copyright (C) 2014 J.-H. Chen and H.-C. Wang. This is an open access article distributed under the Creative Commons Attribution License, which permits unrestricted use, distribution, and reproduction in any medium, provided the original work is properly cited.

\begin{abstract}
The purpose of this study is to construct metal-organic framework (MOF) synthesis heating systems based on fuzzy method for monitoring and automatic control. In this study, the temperature sensing module for measurements sensed values that it through a wireless ZigBee chips and wired DAQ device for real-time data transmission. Because MOF synthesis, often due to different modes of heating or heating instability caused by its nucleation and crystal growth rate, is an important influence, leading to different crystallinity, the use of fuzzy theory to predict the temperature parameter and instant heating MOF synthesis parameters can be adjusted to improve the accuracy of the system. The research system to RS-232 interface module for infrared emission control packets issued and automated control of the furnace through the infrared receiver module. This study is based on a terminal interface window of Visual Basic programming and LabView graphical diagram for control system design. Finally, this research, through a number of experiments to validate the use of fuzzy system development methods and networks, can improve the accuracy of the reaction efficiency MOF sensing and control the heating system.
\end{abstract}

\section{Introduction}

This project is the monitoring and automatic control system for MOF synthesis heating, which required a temperature controller for heating between $90^{\circ} \mathrm{C}$ and $140^{\circ} \mathrm{C}$. The temperature controllers in the market are too expensive and difficult to reach the required temperature within a stable range. The factors affecting the structure of MOF include the coordination of geometry environment that is favored by metal, synthesis temperature history, the ions to balance the number of charge, solvent system, the proportion of metal ion and organic ligands, and the $\mathrm{pH}$ value of reaction solution. The coordination ability of carboxyl is different between hot water condition under high temperature and warm condition in green house. Therefore, the frameworks developed are different. Under high temperature, carboxyl is coordinated with multichelating, easy to form multidimensional structure; however, in room temperature, it is coordinated with single-chelating, easy to form single-dimensional structure.

In this study, we cooperated to design a temperature control system that is able to achieve the requirements of
MOF synthesis to benefit MOF synthesis research. Metalorganic framework, MOF, so called metal-organic coordination polymers, MOCPs, is a porous framework formed by functional groups of organic ligands, such as terephthalic acid, and the metal ion with empty d orbit (such as zinc, nickel, and cobalt) through coordination bond and other interactions, such as hydrogen bond and van der Waals forces. This porous framework can maximize the surface area of material, like porous sponge. If the framework can be changed in processes to reduce the diameter of pore and increase the number of pores, so that the surface area is escalated to increase storage space, then this has an attractive perspective on the application of gas storage.

In a factory in Chunghwa County, a reactor was out of control, and a thermal explosion took place. No casualty was reported in the factory; however, the firefighters arriving at scene for rescue were injured. The whole process areas in the factory were damaged. At the instant of incident, a severe out-of-control reaction of the 15-ton reactor took place. The temperature and pressure of reaction operation rapidly rose. 
TABLE 1: Performance comparison of thermal couple, thermal resistance, and thermistor.

\begin{tabular}{lccc}
\hline Feature & & Type & \\
& Thermocouple & RTD (PT100) & Thermistor \\
\hline Accuracy & Fair & Excellent & Good \\
Stability & Fair & Excellent & $-100 \sim 280^{\circ} \mathrm{C}$ \\
Range & $-185 \sim 1700^{\circ} \mathrm{C}$ & $-15 \sim 70^{\circ} \mathrm{C}$ & $1 \sim-3 \mathrm{~V}$ \\
Sensitivity & $50 \mu \mathrm{V} /{ }^{\circ} \mathrm{F}$ & $0.1 \Omega / /^{\circ} \mathrm{F}$ & $1 \sim 3 \mathrm{~V}$ \\
Output & $0.60 \mathrm{mV}$ & $1 \sim 6 \mathrm{~V}$ & Very sensitive \\
Advantage & Economic and & High precision within & measuring range \\
& range-wide & & \\
\hline
\end{tabular}

The condensate tube on the top of reactor connected to atmosphere and the unlocked manhole cover spitted out the raw materials for reaction and the gas generated by reaction out of control in massive amount. Though massive cooling water was poured in, which is expected to stop the reaction, the expansion of the boiled liquid in the reactor still continued, and the pressure readings were still soaring. Eventually, the reactor exploded, and the top cover of reactor was lifted over. The explosive pressure knocked down the adjacent steel frames and broke the glass at nearby control room and factory [1]. With the two examples above, we learn that the unsound design of temperature control system can cause the occurrence of chemical disaster. Therefore, the stability of temperature control system is important in the future. The factors affecting the structure of MOF include the coordination of geometry environment that is favored by metal, synthesis temperature history, the ions to balance the number of charge, solvent system, the proportion of metal ion and organic ligands, and the $\mathrm{pH}$ value of reaction solution. The coordination ability of carboxyl is different between hot water condition under high temperature and warm condition in green house. Therefore, the frameworks developed are different. Under high temperature, carboxyl is coordinated with multichelating, easy to form multidimensional structure; however, in room temperature, it is coordinated with single-chelating, easy to form a single-dimensional structure.

\section{Literature Review}

MOF, metal-organic framework, is a new type of porous crystal material, whose advantages include high porosity, large surface area, easy synthesis, adjustable framework size, high purity, and excellent crystal [2]. MOF is a ligand polymer assembled by multichelating organic ligands containing oxygen and hydrogen (mostly aromatic acid and polybase) and transition metal ion. In the 20th century, middle of 90 s, the first MOF was synthesized. However, the rate of porosity and the chemical stability were not high. Thus, scientists started to research the new type of ligand polymer formed by positive ions, negative ions, and neutral ligands. Presently, there are a lot of synthesized metal organic frameworks, [3-10], mainly organic negative ion ligand containing carboxyl or those used with $\mathrm{N}$-containing heterocycle organic neutral ligand. Most of these MOFs have high rate of porosity and good chemical stability. MOFs have broader perspectives than other porous materials due to the controllable pore structure and larger surface area, such as adsorption method of separation [1116], catalyst, magnetic material [17], and optical material. In addition, as a super low density porous material, MOF has potential to store massive fuel gas, such as methane [18] and hydrogen [19], which can provide more convenient energy for traffic tools of next generation [20].

The major principle of thermal couple is Seebeck Effect. Thermal couple consists of two different conductors. The metal atoms vibrate with larger amplitude and frequency when temperature rises, causing electron clashing and stopping the flow of electrons, that is, the higher the temperature, the higher the resistance. The electrical properties of materials are related to temperature. This relationship is the theory to measure temperature. When there is a temperature difference between both ends of thermal couple, this thermal couple can generate a voltage signal, whose value is proportional to the temperature difference between both ends of thermal couple. The common contact sensors are thermal couple, thermal resistance, and thermistor. Thermal couple is usually used in industry. The differences among them are listed in Table 1 [21].

ZigBee [22-27] was established by IEEE 802.15.4 team and ZigBee Alliance Organization for hardware and software standards. The MAC layer of ZigBee adopts talk-when-ready mechanism. When there is a request for data transmission, the data are sent immediately. Each sent data package is confirmed by receiver for receipt, who replies with a message for confirmation. If no message is received for confirmation, it means clash occurs, and the data will be sent again. This way greatly increases the reliability of system information transmission [28]. According to the official reports from ZigBee Alliance (ZigBee Alliance, 2005), compared with the other wireless networks, ZigBee has advantages over many ways, such as power consumption, number of network node, transmission range, and system performance. The detailed comparisons are listed in Table 2 [29].

Infrared, such as infrared transmission and infrared photoelectric breaker, utilizes the infrared range from $780 \mathrm{~nm}$ to $1.5 \mu \mathrm{m}$. Thus, the sensors for near-infrared are often used in the range from visible light to near-infrared, as a silicon photoelectric diode with such wavelength. The peak lightemitting wavelength of GaAs element infrared light-emitting diode is 940-950 nm, which human eyes cannot sense [30].

In our daily life, the application of infrared is extensive, such as remote control of television, audio, data transmission among computers and mobile phones, and infrared wireless 
TABLE 2: Performance comparison of various wireless networks.

\begin{tabular}{|c|c|c|c|c|}
\hline \multirow[b]{2}{*}{ Comparison standard } & \multicolumn{4}{|c|}{ Network Type } \\
\hline & $\begin{array}{l}\text { ZigBee } \\
802.15 .4\end{array}$ & GSM/GPRS & $\begin{array}{c}\text { Wi-Fi } \\
802.11 b\end{array}$ & $\begin{array}{c}\text { Blue Tooch } \\
802.15 .1\end{array}$ \\
\hline Applied area & $\begin{array}{l}\text { Monitoring and } \\
\text { control }\end{array}$ & $\begin{array}{l}\text { Wide range voice and } \\
\text { data }\end{array}$ & $\begin{array}{l}\text { Web, Email, and } \\
\text { Video }\end{array}$ & $\begin{array}{l}\text { Replace transmission } \\
\text { wires of computer } \\
\text { peripheral }\end{array}$ \\
\hline System resource & $4 \sim 32 \mathrm{~KB}$ & $16 \mathrm{MB}+$ & $1 \mathrm{MB}+$ & $250 \mathrm{~KB}+$ \\
\hline Battery life (day) & $100 \sim 1000$ & $1 \sim 7$ & $0.5 \sim 5$ & $1 \sim 7$ \\
\hline Network number & $2^{6+}$ & 1 & 32 & 7 \\
\hline Transmission rate $(\mathrm{KB} / \mathrm{s})$ & $20 \sim 250$ & $64 \sim 128+$ & 11000 & 720 \\
\hline Transmission distance (m) & $1 \sim 100+$ & $1000+$ & $1 \sim 100$ & $1 \sim 10+$ \\
\hline System performance & Reliability, power, cost & Cover range, quality & Speed, flexibility & Cost, convenience \\
\hline
\end{tabular}

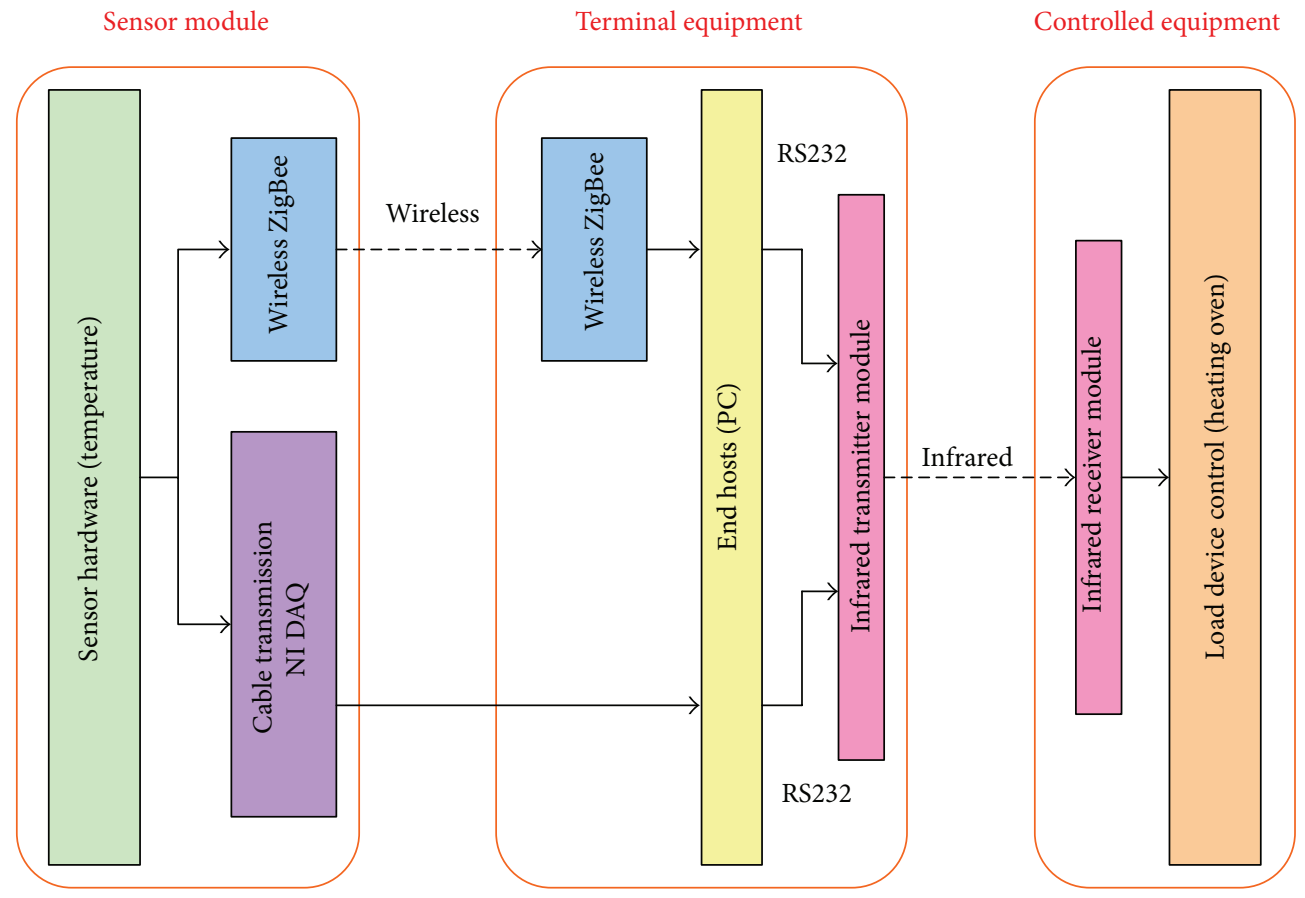

FIGURE 1: System major structure.

microphone. The advantages of infrared are low power consumption, low cost, and simple security review by many countries required for imported products, unlike remote control by radio, which would be different in many countries due to the different regulations for radio with different requirements on frequencies, so as higher costs for security review. However, the disadvantages of infrared remote control are shorter range and interference when used in close range simultaneously on account of the features of light, which would cover each other [31].

Fuzzy Predictive Control experiments using the predictive model based on a kind of model accuracy are low, easily accessible, comprehensive quality control, to facilitate the calculation of the new computer online optimal control methods. Predictive control optimization for specific applications is computational burden of self-adjustment in case of heavier. So he needs to learn a valuable predictive control to promote the idea from other theories methods to compensate for lack of advanced optimization to meet the control requirements. Results and fuzzy control, neural networks and genetic algorithms and another intelligent control, predictive control, strategy would have been achieved by combining the wisdom of predictive control is moving in the direction of development, thus further enhancing the predictive control to face a complex environment, complex objects, and complex tasks processing capacity, expanding the predictive control theory and application fields. Identification of fuzzy control and fuzzy control as a novel method of wisdom in the process of solving the problem of the control of complex systems has shown great potential [32-34].

\section{System Hardware Design}

The system structure mainly consists of sensing modules, terminal units, and controlled equipment, as shown in Figure 1. 


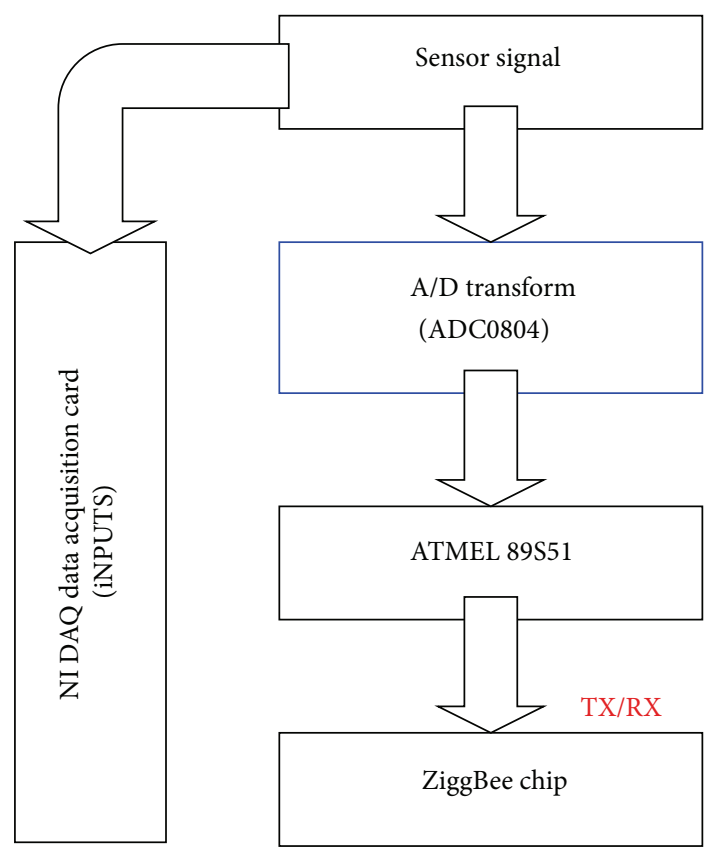

FIGURE 2: Major structure of temperature sensing module hardware.

3.1. Temperature Sensing Module. The signals of J type thermal couple are converted through A/D from analogue signals to digital signals and processed by 8051 . The values of the processed signals are displayed on 7-stage displayer through I/O. Meanwhile, the signals are transmitted through serial port to wireless ZigBee chip for wireless transmission. The signals can be directly sent to NI DAQ data acquisition card for wire transmission, as shown in Figure 2.

The temperature sensing module includes ZigBee circuits, J type thermal couple sensing circuit, infrared receiving circuit, and power supply, as shown in Figure 3.

Temperature sensing circuit diagram is as shown in Figure 4, utilizing the OPA design of IC AD594 and TL084 specialized for J type thermal couple.

3.2. Infrared Emitter and Receiver Module Design. Visual Basic and Labview are used to control RS232 with serial ports for transmission through MAX232 for signal conversion to single chip 8051 for determination with correspondent programs for output pins, through controlling transistor switches to close the pins correspondent to PT2248 and send out the signals from infrared light-emitting diode, to complete the emission, as shown in Figure 5. The wireless infrared emission module includes ZigBee circuits, infrared emission circuits, and power supply, as shown in Figure 5.

When the receiver receives the emitted signals, the signals are decoded by PT2249 and output to 8051 for determination. 8051 controls the transistor switches to conduct SSR to activate the heating oven and utilizes 74LS27 to trigger the external interrupting pin that controls 8051 to achieve the power saving function, as shown in Figure 6, which is the infrared receiver structure. The wire infrared emission module includes infrared emission circuits and power supply, as shown in Figure 6.
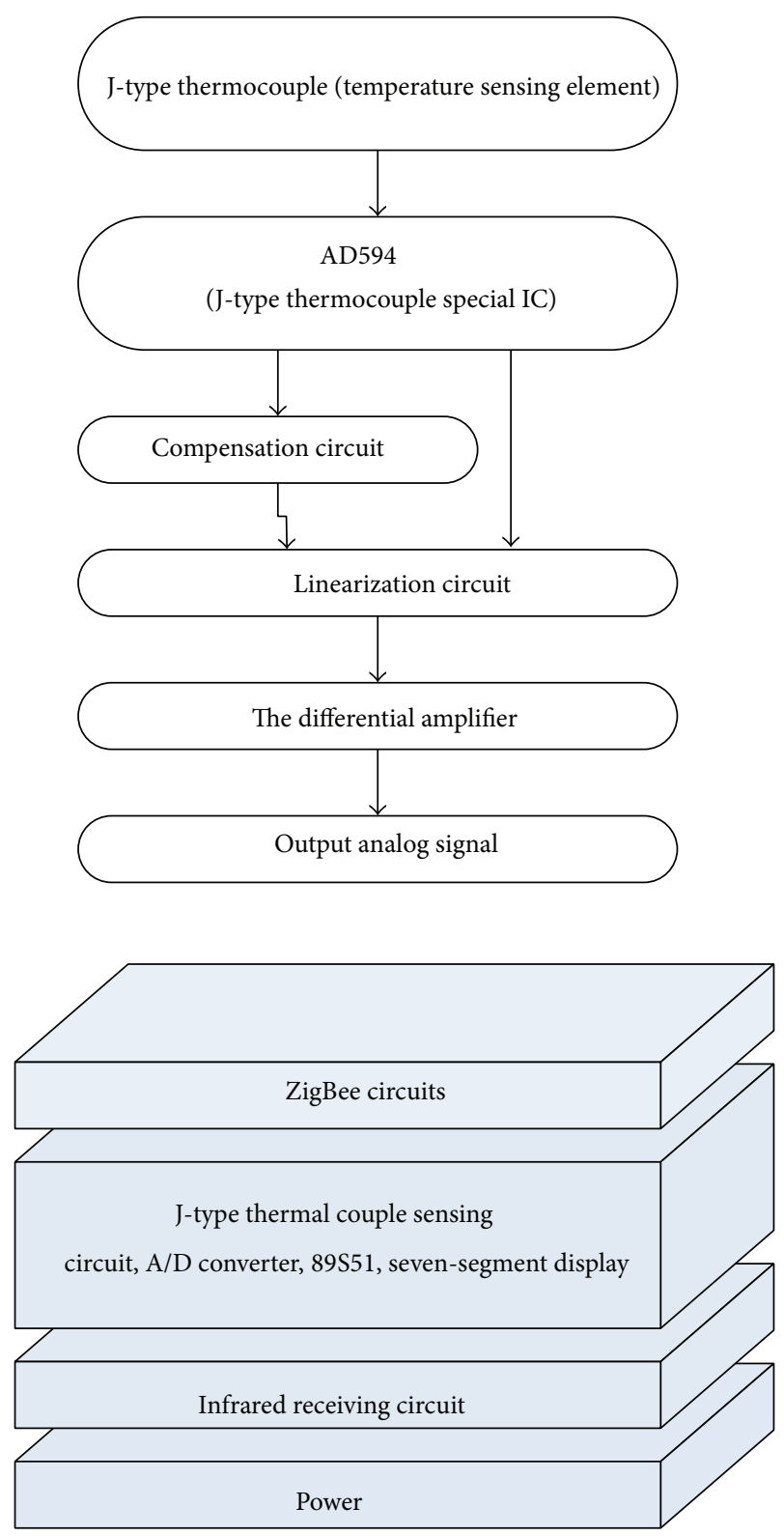

FIGURE 3: Temperature sensing module design.

\section{Graphics User Interface Design}

4.1. Wireless Automatic Monitoring Interface. The wireless monitoring system is designed with Visual Basic graphic window application. This monitoring interface is to display the temperatures measured by the sensing module and the curves of the variations. The statuses of heating oven can be displayed in accordance with the set temperatures, for not heating and heating, respectively, as shown in Figure 7(a). The temperature can be input directly as required by user. After confirm button is clicked, the value will be sent out, as shown in Figure 7(b).

The temperature is set according to the requirements by Department of Chemical Engineering. The value of the sensed temperature obtained at the beginning is smaller than 


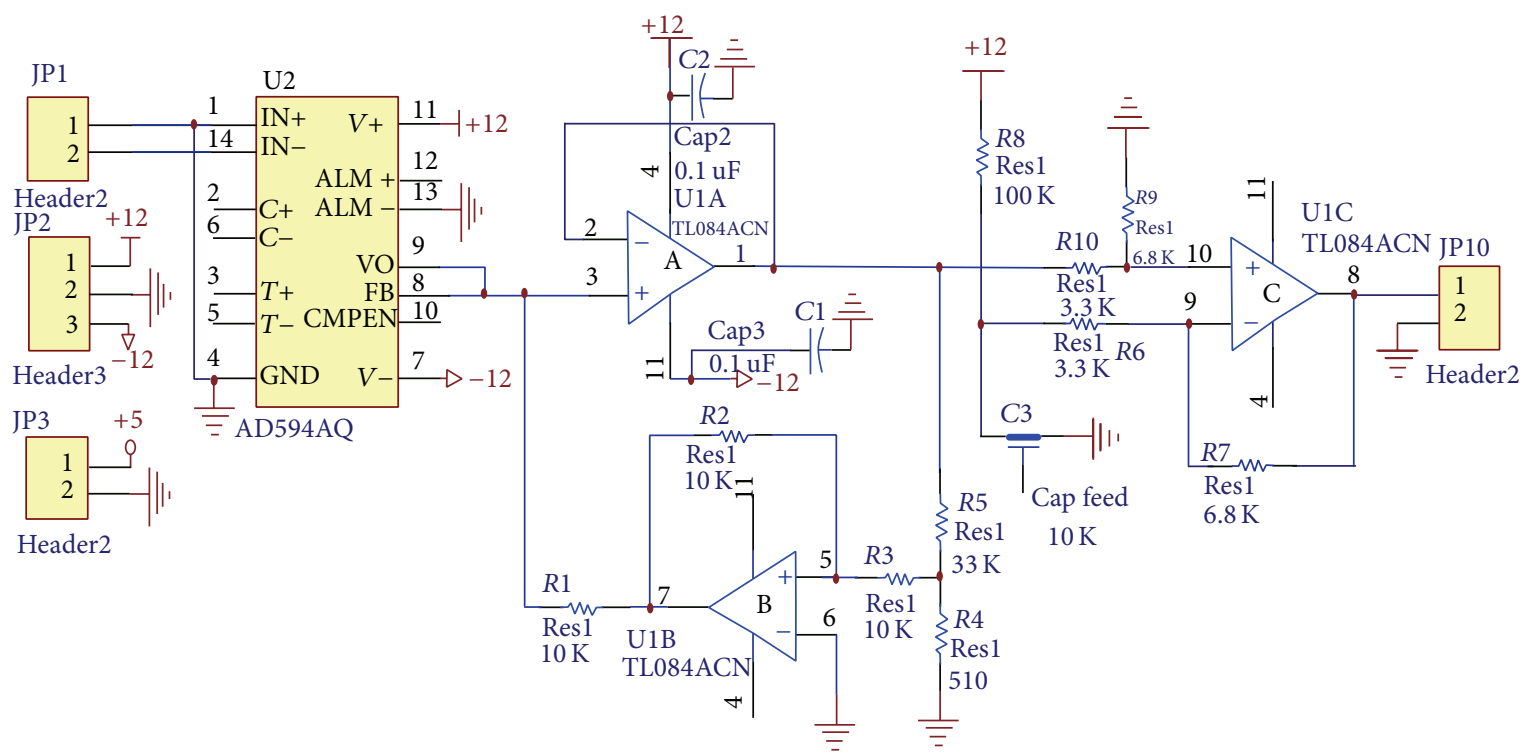

FIgURE 4: Temperature sensing circuit diagram.
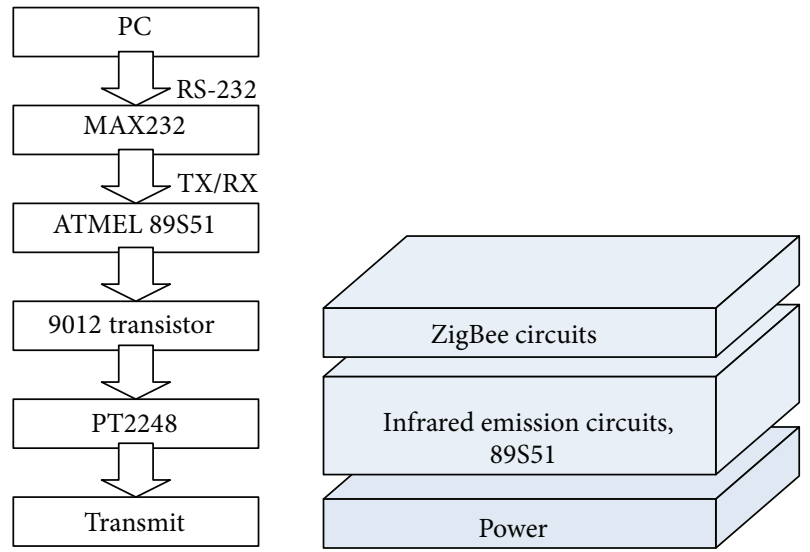

FIGURE 5: Infrared emission structure and wireless infrared emission module design.

the set temperature, 20 degrees Celsius; thus, the heating signal will be automatically emitted. The status displays heating. When the temperature reaches below the set temperature, 20 degrees Celsius, the stop heating signal will be emitted. The status displays not heating. When the temperature reaches below the set temperature, 20 degrees Celsius, the oven will be automatically turned off for 10 minutes, so that the residual heat can increase the temperature to exceed the set temperature, and then the system starts another program. When the temperature is lower than the set temperature by 2 degrees, the heating signal is emitted. On the contrary, when the temperature is higher, the stop heating signal is emitted. The temperature will be fluctuant around the set temperature.

When the sensed temperature is higher than the set temperature, the green light will be lit, and when the sensed temperature is lower than the set temperature, the red light will be lit, as shown in Figure 8(a). The variation curves of sensed temperature in real time are displayed, as shown in

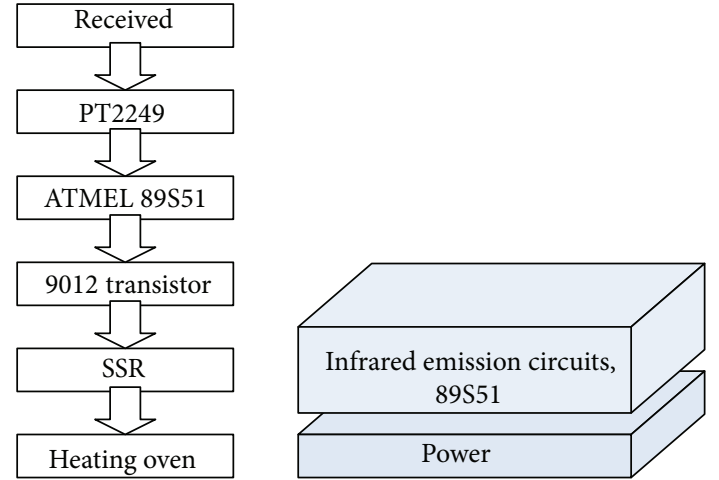

FIGURE 6: Infrared receiver structure and wire infrared emission module design.

Figure 8(b). Click "save photo" to save the variation curves at the moment, as shown in Figure 8(c). With the window shift key on the left upper corner of the monitoring interface, the temperature setting and data records can be switched to each other, as shown in Figure 8(d).

This system will record the temperature variation, heating oven status, and recording time. Every 3600 records will be saved as a file. The rest of the records less than 3600 can be saved as another file with pressing close button and emitting stop signal to prevent contingency, as shown in Figure 9(a). The time to save each record can be set, as shown in Figure 9(b). The data will be saved and recorded in Excel, and the established date will be recorded, as shown in Figure 9(c).

4.2. Wire Automatic Monitoring Interface. The wire automatic monitoring interface is made by LabView graphic control system. There are 3 interfaces, as shown in Figures 10(a) and 10(b), interface for real time display, interface for 


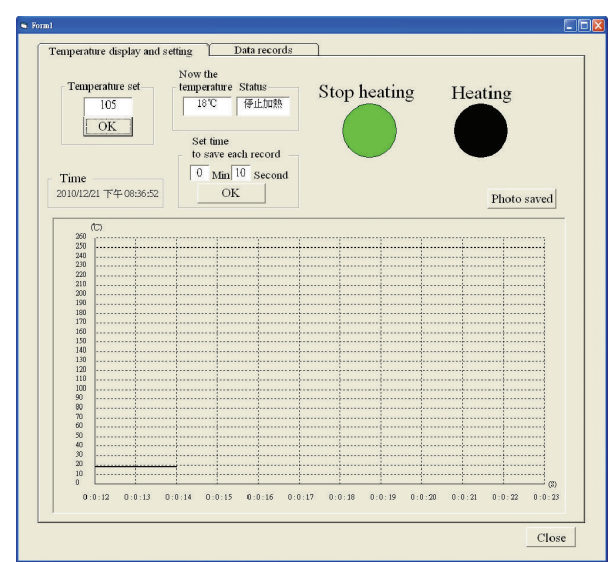

(a)

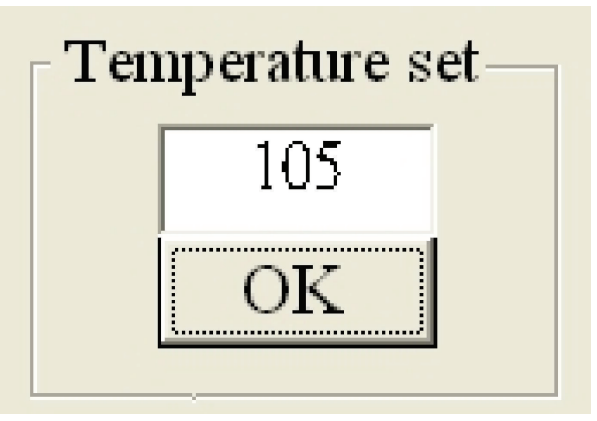

(b)

FIGURE 7: (a) Wireless monitoring interface; (b) temperature setting.

recording file (real time), and interface for recording file (adjustable), respectively.

Figure 10(a) is the interface for real time display. The indicator on the left can show the status for heating. The required temperature can be entered with the temperature setting. The temperature is set in accordance with the requirements by Department of Chemical Engineering. Thus, once the temperature reaches below the set temperature, 20 degrees Celsius, the heating will stop for 10 minutes to dissipate the residual heat. Afterward, the determination for heating will be carried out in accordance with the temperature error of 2 degrees. To terminate the temperature measurement or control, the temperature measurement switch or the control switch can be turned off. The interface for real time display can observe the real time display to learn the time, temperature setting, measured temperature, current status, and measured time. The temperature variation of the heating oven can be learned from the waveform diagram [35-37].

4.3. Interface for Recording File. In the interface for recording file (real time), as shown in Figure 10(a), with the temperature record table of the interface, the values of temperature, set temperature, temperature error, and recording time. The real time access setting on the top, as shown in Figure 10(b), can select the recorded temperatures and the access of waveforms, as well as the customized saving path during recording.

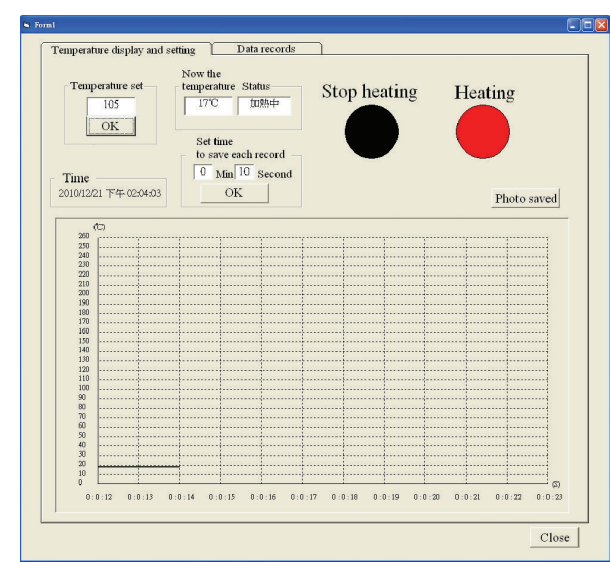

(a)

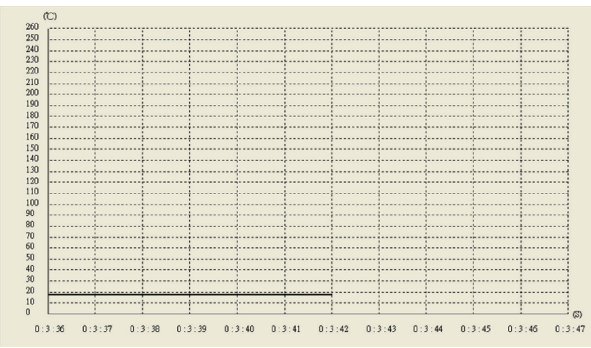

(b)

\section{Photo saved}

(c)

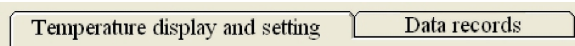

(d)

FIGURE 8: (a) Wireless monitoring heating display, (b) real time temperature variation curve, (c) photo saved, (d) window shift key.

Save the temperature setting, sensed temperature, sensing status, and recording time to Excel spreadsheet, as shown in Figure 10(c). In the option for saving file of waveform records, there are options for automatic or manual saving. Automatic saving will save a.bmp graphic file with temperature data by 60 records in 60 seconds to the specified path. Manual saving can snapshot the current waveform with button switch "waveform snapshot" and establish a graphic file to the specified saving path.

In the interface for recording file (real time), as shown in Figure 10(d), in the column to set the interval, the interval time for saving can be set as required. It can be data (Excel file) or waveforms (.bmp) to be saved. Network transmission technology can reach anywhere. MOF synthesis heating processes can be remotely monitored with IE by the Web Publish Tool menu built in LabView graphic control application, as shown in Figure 11(a). 


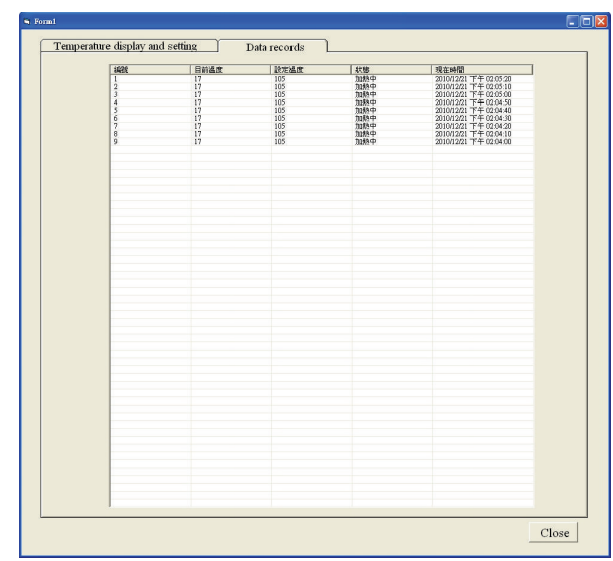

(a)

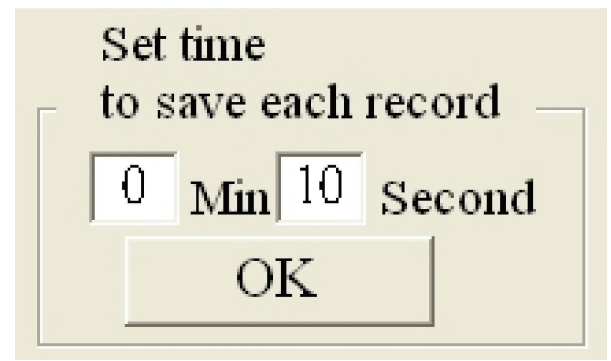

(b)

\begin{tabular}{|c|c|c|c|c|c|c|c|}
\hline & A & B & $\mathrm{C}$ & D & E & $\mathrm{F}$ & G \\
\hline 1 & 建表日期 & \multicolumn{3}{|c|}{ 2010/12/4 下午 $10: 41: 00$} & & & \\
\hline \multicolumn{8}{|l|}{2} \\
\hline 3 & 編號 & 目前溫度 & 設定溫度 & 狀態 & 現在時間 & & \\
\hline 4 & & $26^{\circ} \mathrm{C}$ & $92^{\circ} \mathrm{C}$ & 加熱中 & $2010 / 12 / 4$ & 下午 $02: 37: 2$ & \\
\hline 5 & & $231^{\circ} \mathrm{C}$ & $92^{\circ} \mathrm{C}$ & 加熱中 & $2010 / 12 / 4$ & 下午 02:37:5 & \\
\hline 6 & & $38^{\circ} \mathrm{C}$ & $92^{\circ} \mathrm{C}$ & 加熱中 & $2010 / 12 / 4$ & 下午 $02: 38: 2$ & \\
\hline 7 & & $145^{\circ} \mathrm{C}$ & $92^{\circ} \mathrm{C}$ & 加熱中 & $2010 / 12 / 4$ & 下午 $02: 38: 5$ & \\
\hline 8 & & $54^{\circ} \mathrm{C}$ & $92^{\circ} \mathrm{C}$ & 加熱中 & $2010 / 12 / 4$ & 下午 $02: 39: 2$ & \\
\hline 9 & & $563^{\circ} \mathrm{C}$ & $92^{\circ} \mathrm{C}$ & 加熱中 & $2010 / 12 / 4$ & 下午 $02: 39: 5$ & \\
\hline 10 & & $73^{\circ} \mathrm{C}$ & $92^{\circ} \mathrm{C}$ & 加熱中 & $2010 / 12 / 4$ & 下午 $02: 40: 2$ & \\
\hline 11 & & $386^{\circ} \mathrm{C}$ & $92^{\circ} \mathrm{C}$ & 加熱中 & $2010 / 12 / 4$ & 下午 $02: 40: 5$ & \\
\hline 12 & & $93^{\circ} \mathrm{C}$ & $92^{\circ} \mathrm{C}$ & 停止加熱 & $2010 / 12 / 4$ & 下午 $02: 41: 2$ & \\
\hline 13 & & $100^{\circ} \mathrm{C}$ & $92^{\circ} \mathrm{C}$ & 停止加熱 & $2010 / 12 / 4$ & 下午 $02: 41: 5$ & \\
\hline 14 & & $106^{\circ} \mathrm{C}$ & $92^{\circ} \mathrm{C}$ & 停止加熱 & $2010 / 12 / 4$ & 下午 $02: 42: 2$ & \\
\hline 15 & & $2110^{\circ} \mathrm{C}$ & $92^{\circ} \mathrm{C}$ & 停止加㷊 & $2010 / 12 / 4$ & 下午 $02: 42: 5$ & \\
\hline 16 & & $310^{\circ} \mathrm{C}$ & $92^{\circ} \mathrm{C}$ & 停止加熱 & $2010 / 12 / 4$ & 下午 $02: 43: 2$ & \\
\hline 17 & & $+114^{\circ} \mathrm{C}$ & $92^{\circ} \mathrm{C}$ & 停止加熱 & $2010 / 12 / 4$ & 下午 02:43:5 & \\
\hline
\end{tabular}

(c)

Figure 9: (a) Temperature status data saving interface, (b) set time to save each record, (c) wireless data saved file.

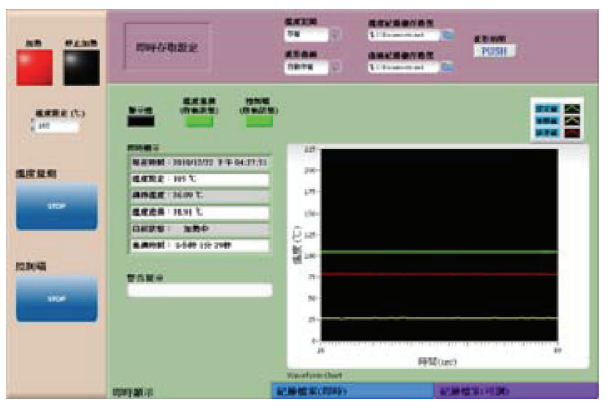

(a)

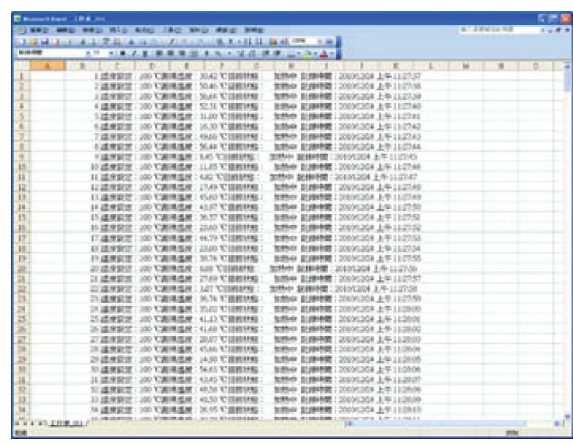

(c)

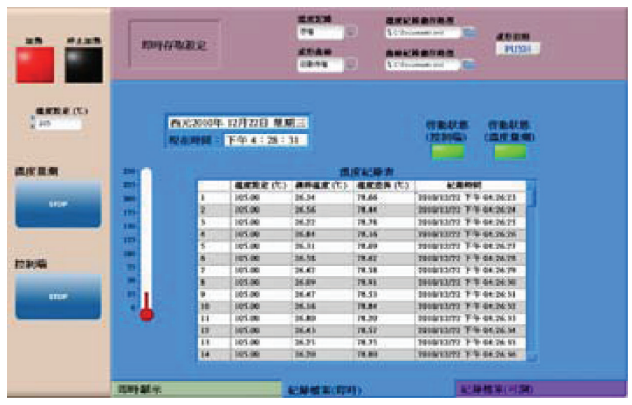

(b)

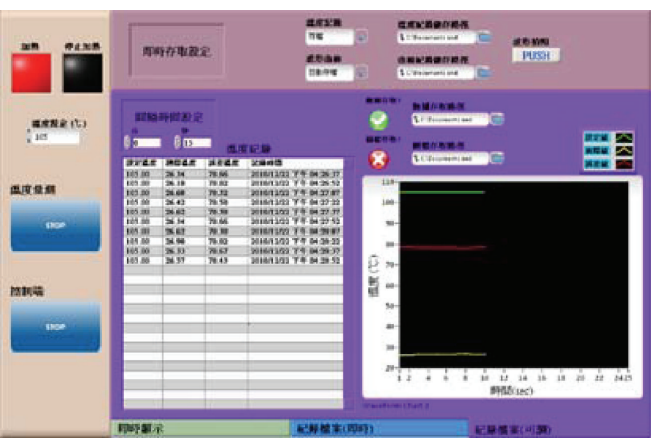

(d)

Figure 10: (a) Real time display interface, (b) recording file (real time) interface, (c) limited data saving file, (d) recording file (adjustable). 


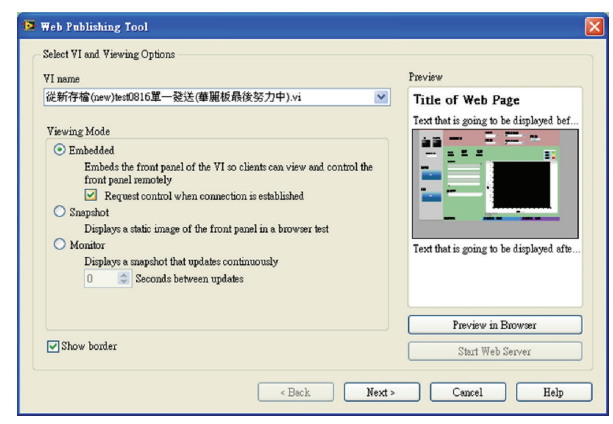

(a)

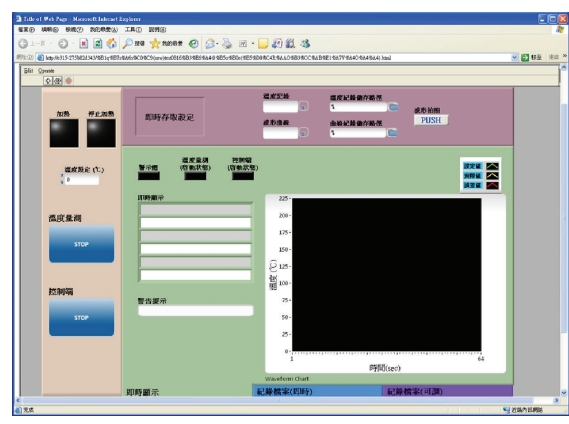

(b)

FIgure 11: (a) Web Publish Tool Setting menu, (b) IE remote monitoring and control.

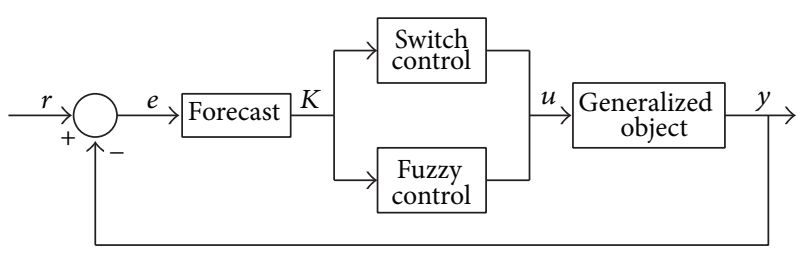

FIGURE 12: Dual-mode fuzzy predictive control system structure in this study.

Link program (.vi) to the website it provides, as shown in Figure 11(b). Monitoring, controlling, and accessing the data of heating oven can be done anywhere. This interface can be opened with IE, and the webpage of control and monitoring can be displayed on computer. However, if IE is used for remote monitoring and control, the fixed IP should be used, and the firewall and antivirus software should be turned off $[38,39]$.

\section{Predictive Fuzzy Control System}

In the general fuzzy control's foundation introduces one kind of forecast fuzzy control system. This method is simple, fast, and accurate; the over modulation is small as well as parameter variation is insensitive and so characteristics can facilitate the use monolithic computer system realizes.

Figure 12 is a dual-mode fuzzy predictive control system structure in this study. It is part of the prediction, switching the control section and fuzzy control, and direct objects Guangyi digital feedback control system.

When controls starts, deviation $e=y-r$ is larger, namely when deviation $|e| \geq\left|E_{M}\right|$ (for double model control when the $e$ boundary value) and system's control quantity takes $+U_{M}$ or $-U_{M}$, the implementation of nonlinear switching control. When deviation $e$ reduces gradually, when it is smaller than the predetermined transform boundary value $\left(|e|<\left|E_{M}\right|\right)$, it carries on the procedure cut and implements the forecast fuzzy control. Like this both can speed up the excessive process and can guarantee system over modulation is small, or even does not have the over modulation, thus obtains the good control quality. Assumed to be the actual controlled object, dynamics can be described using the following formula (where parameters are unknown):

$$
\begin{aligned}
y(k) & +a_{1} y(k-1)+\cdots+a_{n} y(k-n) \\
= & b_{1} u(k-m-1)+\cdots b_{n} u(k-m-n) \\
& +e(k)+c_{1} e(k-1)+\cdots c_{n} e(k-n) .
\end{aligned}
$$

Among (1), $u(k)$ and $y(k)$, respectively are, by controlled member, input and output; $e(k)$ is the white noise interference; $m$ is the transmission delay of the controlled object; $a_{1}, b_{1}, c_{1}, \ldots, a_{n}, b_{n}, c_{n}$ are the coefficients. Set a predictive model, that is, according to time $k$ beforehand data, $y(k), y(k-1), \ldots$ and $u(k), u(k-1), \ldots$ the prediction $y(k+$ $m+1)$, then the adaptive control theory, prediction model's equation is

$$
\begin{aligned}
y(k+ & m+1)+a_{1} y(k)+\cdots+a_{n} y(k-p+1) \\
= & \beta_{0} u(k)+\beta_{1} u(k-1) \\
& +\cdots+\beta_{L} u(k-L)+\varepsilon(k+m+1) .
\end{aligned}
$$

Among (2), $\varepsilon(k+m+1)$ is the deviation of prediction model. That the vector is

$$
\begin{gathered}
X^{T}(k)=[-y(k),-y(k-1), \ldots,-y(k-p+1), \\
u(k-1), \ldots, u(k-L)] .
\end{gathered}
$$

And define the parameter vector:

$$
\theta^{T}(k)=\left[a_{1}, a_{2}, \ldots, a_{p}, \beta_{1}, \beta_{2}, \ldots, \beta_{p}\right] .
$$

Then the prediction model simplification is

$$
y(k)=\beta_{0} u(k-m-1)+X^{T}(k-m-1) \theta+\varepsilon(k) .
$$


Regarding the parameter vector $\theta$ estimate, we can use simply smallest two rides the recursion algorithm; its recursion type is

$$
\begin{aligned}
\hat{\theta}(k)=\widehat{\theta}(k)+R(k) & \\
\times & {\left[y(k)-\beta_{0} u(k-m-1)\right.} \\
& \left.-X^{T}(k-m-1) \widehat{\theta}(k)\right], \\
R(k)= & P(k) \times(k-m-1) \\
& \times\left[1+X^{T}(k-m-1) p(k) \times(k-m-1)\right]^{-1}, \\
P(k+1)= & P(k)-R(k) \\
& \times\left[1+X^{T}(k-m-1) P(k)\right. \\
& \quad \times(k-m-1)] R^{T}(k) .
\end{aligned}
$$

Among (6), $\widehat{\theta}(k)$ represents the time $k$ of the parameter vector estimate, $P(k)$ is the $m \times m$ matrix; its dimension depends on the number of unknown parameters and has nothing to do with the number of measurements.

This allows (2) to find $y(k)$ of the predicted value and thus find the prediction deviation $e$ and change in the deviation rate of prediction $d e$, If the given value is $r$, then one has

$$
e=y(k)-r, \quad d e=y(k-1)-y(k) .
$$

After $e$ and de entire quantification and fuzzy, this study can use the simple belt modification factor based on the fuzzy control rule:

$$
U=-[\alpha E+(1-\alpha) d e] .
$$

Among (8), $U$ is the control quantity size; $\alpha$ is the modification factor; $0<\alpha<1$; Figure 13 is the predicted fuzzy control of a computer flow chart.

This predictive fuzzy control is based on the evaluation in the state, through the alternate values of control instructions and the simulation results of evaluation to determine the operational amount of output. It is the state evaluation of the difference lies in the simulation that it predicts the output state. Prevent the output does not fully comply with the current state of evaluation errors. Based on state evaluation forecast, fuzzy control rule description is as follows. If instructions $u$ is $C, x$ is $A$, and $y$ is the $B$ were established, then the control command is $C$.

Figure 14 is based on the condition appraisal prediction fuzzy control structure. In the chart, the state evaluation is the multiobjective fuzzy appraisals and uses the fuzzy subset to evaluate a variety of control performance Index; the system simulation is according to the controlled member the model, to forecast the operational order and the current condition carries on the system simulation; Control rules are based on the state of the system to determine the amount of control of the operation of the system.

Expressed are the following types of operating rules.

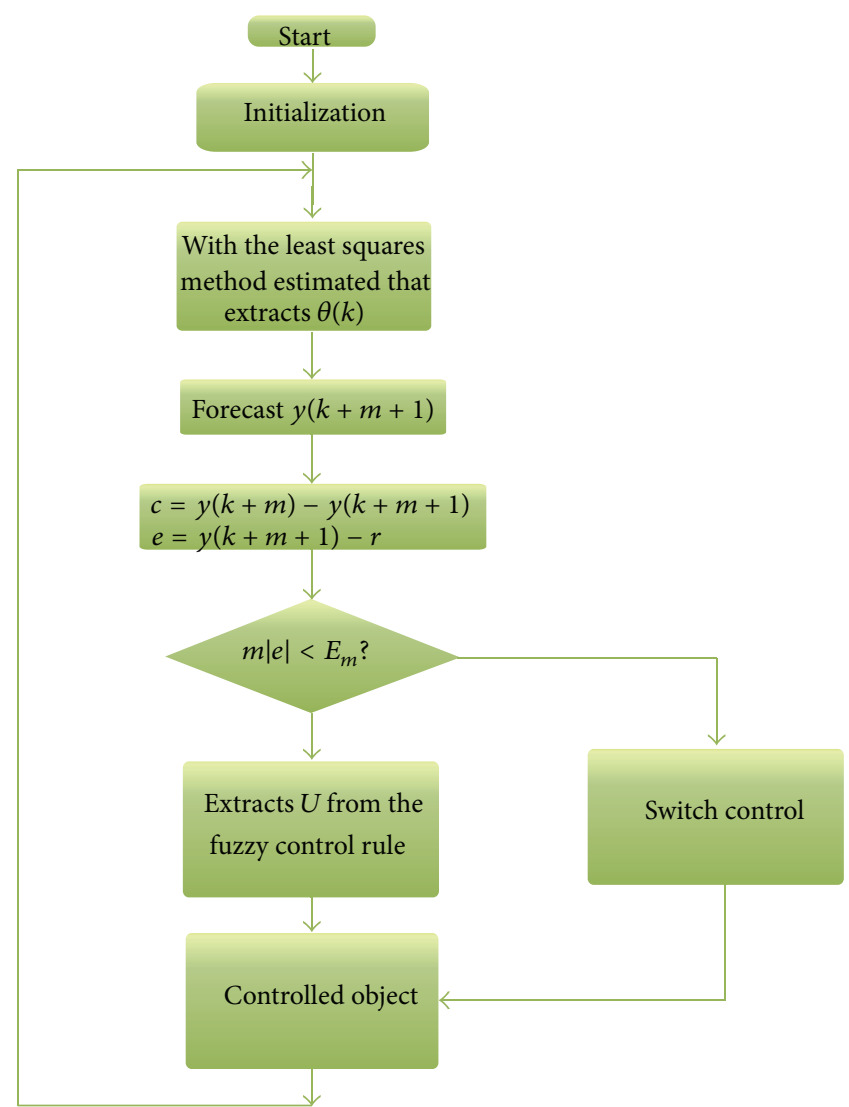

FIgURE 13: The predicted fuzzy control of a computer flow chart.

If $u$ is $C \rightarrow X_{1}$ and $X_{2}$ for $A$ to $B$, then $u$ take the $C$ value. Antecedent of the rule itself is by an inference $(\rightarrow)$ composition.

Figure 15 expressed its fuzzy logic inference process.

Predictive fuzzy control in every moment is based on the status of the controlled object; the implementation of control instructions may cause the results to predict performance changes; carrying out these is advantageous in realizing the control objective control command. This, which may avoid transmitting, has the possibility to cause the adverse consequences control command and thus enhanced the systems operation security and the controllability. This way may use in the significant dynamic model, but cannot carry on the target system carry on the track [40-43].

\section{MOF Synthesis Heating Experiment Result}

In the first experiment, the temperatures are set as 105 degrees for 8 hours of operation. The data are saved every 30 seconds. The temperature curve is established with the saved data, as shown in Figure 16(a).

In the second experiment, the temperature is set as 130 degrees for 4 hours of operation. The data are saved every 5 seconds. The temperature curve is established with the saved data, as shown in Figure 16(b). The product of temperature sensing module is shown as Figure 17(a). The product of wireless infrared emission module is shown as Figure 17(b). 


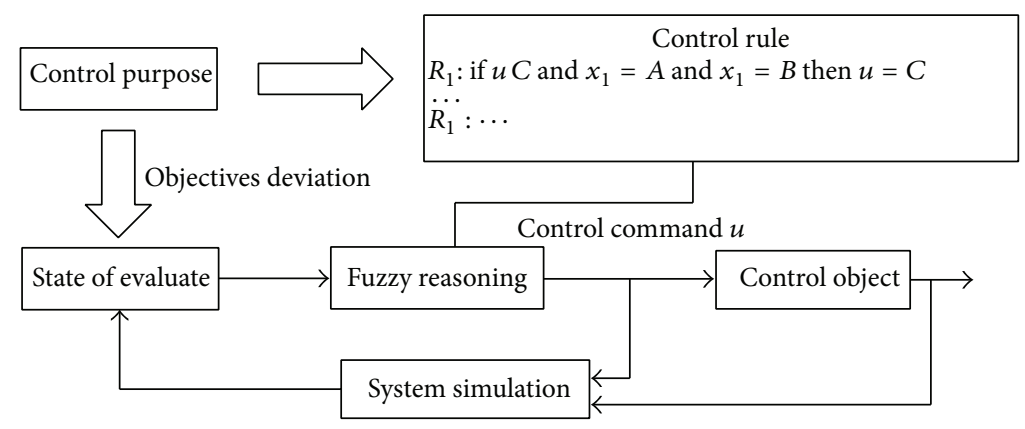

FIGURE 14: Fuzzy control structure based on the condition appraisal prediction.

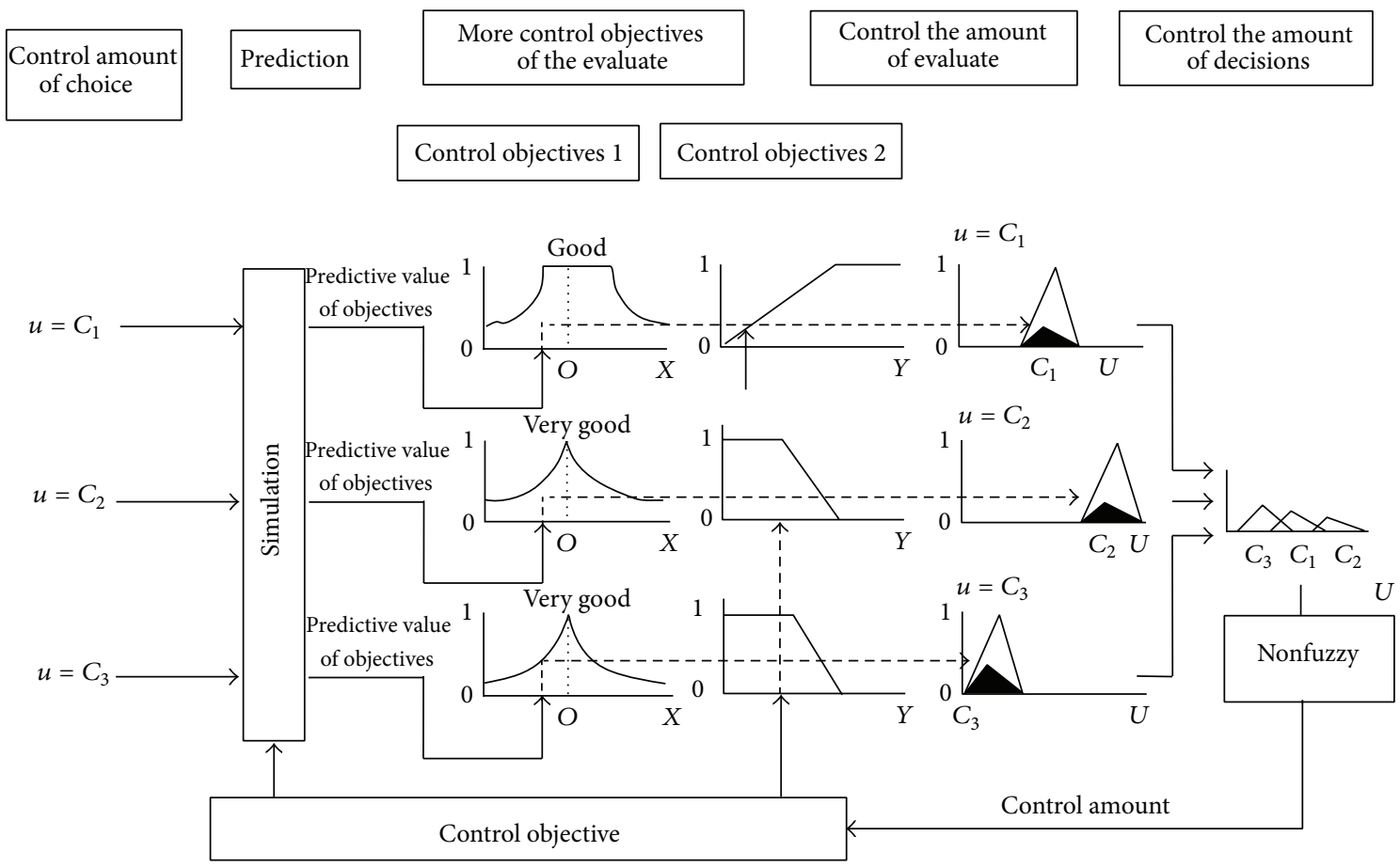

FIGURE 15: This study expressed its fuzzy logic inference process.

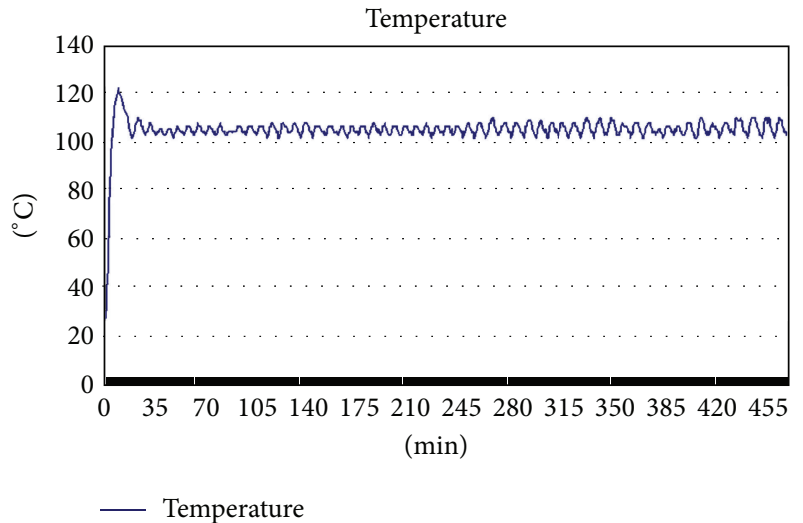

(a)

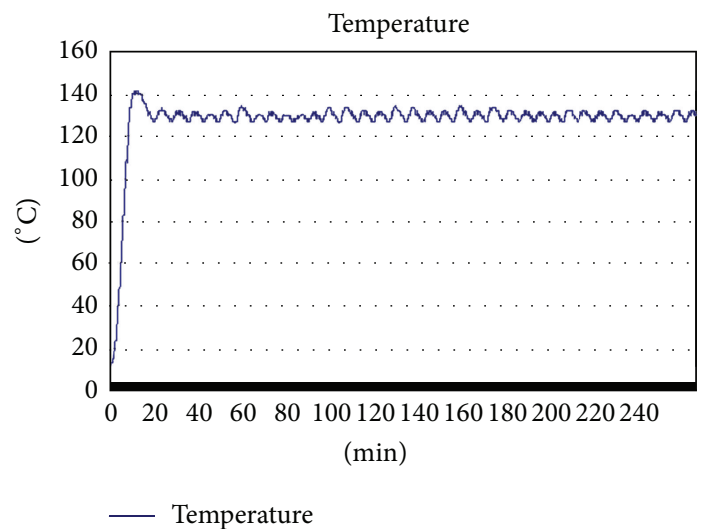

(b)

FIGURE 16: (a) First heating experiment temperature curve, (b) second heating experiment temperature curve. 


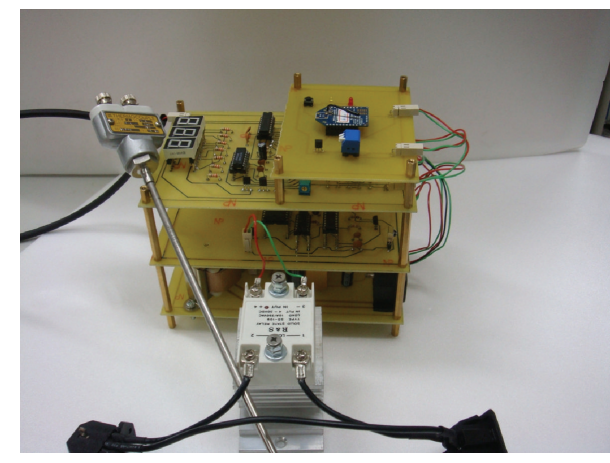

(a)

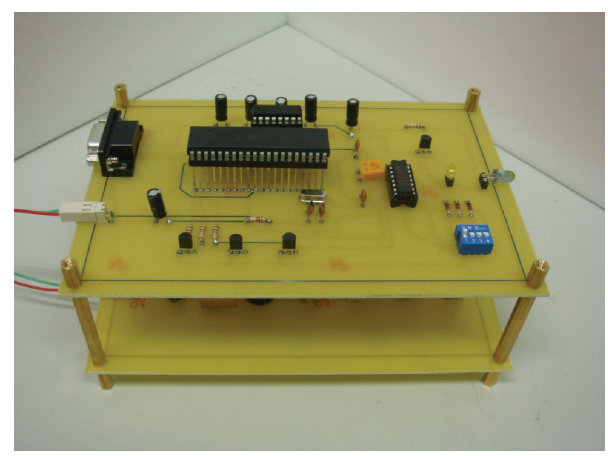

(c)

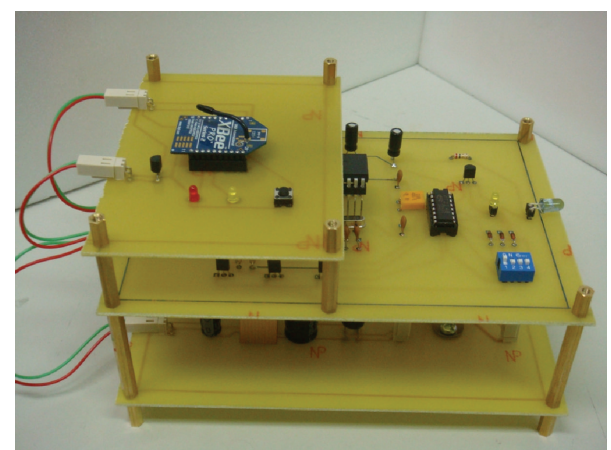

(b)

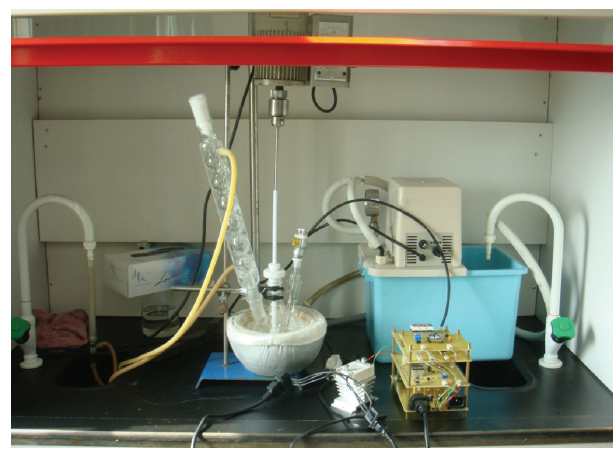

(d)

Figure 17: (a) Temperature sensing module, (b) wireless infrared emission module, (c) wire infrared emission module, (d) MOF synthesis heating experiment.

The product of wire infrared emission module is shown as Figure 17(c). The actual operation of MOF synthesis heating experiment is shown as Figure 17(d).

\section{Conclusions and Future Work}

This study is the monitoring and automatic control system for MOF synthesis heating via fuzzy method. This project uses the temperature sensing module, infrared control module, DAQ wire transmission, ZigBee wireless transmission technology, and LabView graphic control system and Visual Basic graphic window as operation interfaces to construct the whole monitoring and control system. This study practical results are as follows. (1) The temperature sensing module made by J type thermal couple is finished. (2) System's transmission unit by the ZigBee wireless and DAQ Data Acquisition Card is Constructed. (3) The infrared receiving and emitting control module to send these messages and real-time information is employed. (4) The user interface is designed including monitoring, controlling, and recording functions. (5) In the MOF synthesis heating experiment, according to the documents of MOF, the temperature is maintained between 130 and 105 degrees. The operations with different time can obtain better frameworks.

To reach the purpose of the sequential control from starting of heating to the setting the temperature and maintaining it within the temperature range, it is necessary to carry out many experiments for measurement, evaluation, and control to obtain the best temperature control processes. Through utilizing fuzzy control [44] and PID control [45] theory in automatic control, the best heating temperature processes can be achieved. Through this control, MOF can be heated and synthesized to the most ideal crystal structure.

Afterward, combined with the other teams in the laboratory, which are intelligent environment monitoring and control and automatic system and RFID personal monitoring and control system, this system can achieve the control for the conditions required by the working environment and the safety of controlling the heating system to reduce the influence by the environmental factors to reaction and the harms by human factors to accomplish a working environment with high stability, high efficiency, and high accuracy, as well as the safety of experiment and the best result, to complete a more humanized MOF synthesis heating processes monitoring and control system [46].

\section{Conflict of Interests}

The authors declare that there is no conflict of interests regarding the publication of this paper.

\section{Acknowledgments}

This research was supported by the National Science Council of Taiwan under Grant NSC 99-2815-C-167-009-E. The 
authors would like to thank the National Chin-Yi University of Technology, Taiwan, for financially supporting this research.

\section{References}

[1] M. Abuswer, P. Amyotte, and F. Khan, "A quantitative risk management framework for dust and hybrid mixture explosions," Journal of Loss Prevention in the Process Industries, vol. 26, no. 2, pp. 283-289, 2013.

[2] D.-W. Lim, J. W. Yoon, K. Y. Ryu, and M. P. Suh, "Magnesium nanocrystals embedded in a metal-organic framework: hybrid hydrogen storage with synergistic effect on physi- and chemisorption," Angewandte Chemie-International Edition, vol. 51, no. 39, pp. 9814-9817, 2012.

[3] J. L. C. Rowsell and O. M. Yaghi, "Metal-organic frameworks: a new class of porous materials," Microporous and Mesoporous Materials, vol. 73, no. 1-2, pp. 3-14, 2004.

[4] O. M. Yaghi, M. O'Keeffe, N. W. Ockwig, H. K. Chae, M. Eddaoudi, and J. Kim, "Reticular synthesis and the design of new materials," Nature, vol. 423, no. 6941, pp. 705-714, 2003.

[5] S. Kitagawa, R. Kitaura, and S.-I. Noro, "Functional porous coordination polymers," Angewandte Chemie-International Edition, vol. 43, no. 18, pp. 2334-2375, 2004.

[6] Y. He, Z. Guo, S. Xiang et al., "Metastable interwoven mesoporous metal-organic frameworks," Inorganic Chemistry, vol. 52, no. 19, pp. 11580-11584, 2013.

[7] C. J. Kepert, T. J. Prior, and M. J. Rosseinsky, "Hydrogen bonddirected hexagonal frameworks, based on coordinated 1,3,5benzenetricarboxylate," Journal of Solid State Chemistry, vol. 152, no. 1, pp. 261-270, 2000.

[8] Y. Liu, J. F. Eubank, A. J. Cairns et al., "Assembly of MetalOrganic Frameworks (MOFs) based on indium-trimer building blocks: a porous MOF with soc topology and high hydrogen storage," Angewandte Chemie-International Edition, vol. 46, no. 18, pp. 3278-3283, 2007.

[9] D. Saha and S. Deng, "Hydrogen adsorption on metal-organic framework MOF-177," Tsinghua Science and Technology, vol. 15, no. 4, pp. 363-376, 2010.

[10] C. Y. Lee, Y.-S. Bae, N. C. Jeong et al., "Kinetic separation of propene and propane in metal-organic frameworks: controlling diffusion rates in plate-shaped crystals via tuning of pore apertures and crystallite aspect ratios," Journal of the American Chemical Society, vol. 133, no. 14, pp. 5228-5231, 2011.

[11] Z. Chen, S. Xiang, H. D. Arman et al., "Three-dimensional pillar-layered copper(II) metal-organic framework with immobilized functional $\mathrm{OH}$ groups on pore surfaces for highly selective $\mathrm{CO}_{2} / \mathrm{CH}_{4}$ and $\mathrm{C}_{2} \mathrm{H}_{2} / \mathrm{CH}_{4}$ gas sorption at room temperature," Inorganic Chemistry, vol. 50, no. 8, pp. 3442-3446, 2011.

[12] J. An and N. L. Rosi, "Tuning $\mathrm{MOF} \mathrm{CO}_{2}$ adsorption properties via cation exchange," Journal of the American Chemical Society, vol. 132, no. 16, pp. 5578-5579, 2010.

[13] Z. R. Herm, J. A. Swisher, B. Smit, R. Krishna, and J. R. Long, "Metal-organic frameworks as adsorbents for hydrogen purification and precombustion carbon dioxide capture," Journal of the American Chemical Society, vol. 133, no. 15, pp. 5664-5667, 2011.

[14] D. Dubbeldam, C. J. Galvin, K. S. Walton, D. E. Ellis, and R. Q. Snurr, "Separation and molecular-level segregation of complex alkane mixtures in metal-organic frameworks," Journal of the
American Chemical Society, vol. 130, no. 33, pp. 10884-10885, 2008.

[15] J. Rother, T. Fieback, R. Seif, and F. Dreisbach, "Characterization of solid and liquid sorbent materials for biogas purification by using a new volumetric screening instrument," Review of Scientific Instruments, vol. 83, no. 5, Article ID 055112, 7 pages, 2012.

[16] H. Furukawa, K. E. Cordova, M. O'Keeffe, and O. M. Yaghi, "The chemistry and applications of metal-organic frameworks," Science, vol. 341, no. 6149, 2013.

[17] H.-L. Jiang, T. A. Makal, and H.-C. Zhou, "Interpenetration control in metal-organic frameworks for functional applications," Coordination Chemistry Reviews, vol. 257, no. 15-16, pp. 2232-2249, 2013

[18] Y. He, W. Zhou, T. Yildirim, and B. Chen, "A series of metalorganic frameworks with high methane uptake and an empirical equation for predicting methane storage capacity," Energy and Environmental Science, vol. 6, no. 9, pp. 2735-2744, 2013.

[19] S. K. Brand, Y. J. Colón, R. B. Getman, and R. Q. Snurr, "Design strategies for metal alkoxide functionalized metalorganic frameworks for ambient temperature hydrogen storage," Microporous and Mesoporous Materials, vol. 171, pp. 103109, 2013.

[20] W. Wei, J. Fang, H. Kong, J. Han, and H. Chang, "Synthesis and applications for materials of metallorganic frameworks," Progress in Chemistry, vol. 17, no. 6, pp. 1110-1115, 2005.

[21] R. K. Kamat and G. M. Naik, "Thermistors-in search of new applications, manufacturers cultivate advanced NTC techniques," Sensor Review, vol. 22, no. 4, pp. 334-340, 2002.

[22] D.-M. Han and J.-H. Lim, "Design and implementation of smart home energy management systems based on ZigBee," IEEE Transactions on Consumer Electronics, vol. 56, no. 3, pp. 14171425,2010

[23] D.-M. Han and J.-H. Lim, "Smart home energy management system using IEEE 802.15.4 and zigbee," IEEE Transactions on Consumer Electronics, vol. 56, no. 3, pp. 1403-1410, 2010.

[24] S. K. Korkua and K. Thinsurat, "Design of ZigBee based WSN for smart demand responsive home energy management system," in Proceedings of the 13th International Symposium on Communications and Information Technologies (ISCIT '13), pp. 549-5554, 2013.

[25] H. Yang, L. Yang, and S.-H. Yang, "Hybrid Zigbee RFID sensor network for humanitarian logistics centre management," Journal of Network and Computer Applications, vol. 34, no. 3, pp. 938-948, 2011.

[26] K. Malhi, S. C. Mukhopadhyay, J. Schnepper, M. Haefke, and H. Ewald, "A Zigbee-based wearable physiological parameters monitoring system," IEEE Sensors Journal, vol. 12, no. 3, pp. 423 430, 2012.

[27] C. Gezer and C. Buratti, "A ZigBee smart energy implementation for energy efficient buildings," in Proceedings of the 73rd IEEE Vehicular Technology Conference (VTC '11), pp. 1-5, May 2011.

[28] E. Mok and Y. K. Yeung, "ZigBee network positioning with support of Real-Time Kinematic GPS and terrestrial measurements," Survey Review, vol. 45, no. 329, pp. 81-87, 2013.

[29] K.-Y. Lu and J.-S. Lu, "A study on the healthcare monitoring system using ZigBee sensor networks," Journal of National United University, vol. 7, no. 1, pp. 235-250, 2010.

[30] P.-W. Chen, K.-S. Ou, and K.-S. Chen, "IR indoor localization and wireless transmission for motion control in smart building 
applications based on wiimote technology," in Proceedings of the SICE Annual Conference, pp. 1781-1785, August 2010.

[31] A. J. Soares Boaventura and N. B. Carvalho, "Feasibility of a battery-less wirelessly-powered RFID remote control system," in Proceedings of the IEEE Wireless Power Transfer (WPT '13), pp. 139-142, May 2013.

[32] W.-T. Sung, J.-H. Chen, and K.-W. Chang, "Mobile physiological measurement platform with cloud and analysis functions implemented via IPSO," IEEE Sensors Journal, vol. 14, no. 1, pp. 111-123, 2014.

[33] W.-T. Sung and C. Hsu, "Intelligent environment monitoring system based on innovative integration technology via PSoC platform and ZigBee network," IET Communications, vol. 7, no. 16, pp. 1789-1801, 2013.

[34] W.-T. Sung, J.-H. Chen, and K.-Y. Chang, "Trust function for multi-physiological signals fusion," Measurement, vol. 47, no. 1, pp. 827-840, 2014.

[35] J. Tao, N. Wang, and R. Zhang, "GA based fuzzy neural network generalized predictive control method," in Proceedings of the 32nd Chinese Control Conference, pp. 4062-4067, 2013.

[36] P. Hajebi and S. M. T. Almodarresi, "Online adaptive fuzzy logic controller using genetic algorithm and neural network for Networked Control Systems," in Proceedings of the 15th International Conference on Advanced Communication Technology (ICACT '13), pp. 88-98, January 2013.

[37] D. Pelusi, "On designing optimal control systems through genetic and neuro-fuzzy techniques," in Proceedings of the 11th IEEE International Symposium on Signal Processing and Information Technology (ISSPIT '11), pp. 134-139, December 2011.

[38] M. A. Jeffril and N. Sariff, “The integration of fuzzy logic and artificial neural network methods for mobile robot obstacle avoidance in a static environment," in Proceedings of the $3 \mathrm{rd}$ IEEE International Conference on System Engineering and Technology (ICSET '13), pp. 325-330, 2013.

[39] Y. Jing, K. Zhang, and J. Xiao, "Modeling of gap sensor for high-speed maglev train based on fuzzy neural network," in Proceedings of the 8th International Conference on Fuzzy Systems and Knowledge Discovery (FSKD '11), pp. 650-654, July 2011.

[40] R.-J. Wai, Z.-W. Yang, and C.-Y. Shih, "Direct adaptive fuzzyneural-network control for robot manipulator by using only position measurements," in Proceedings of the 5th IEEE Conference on Industrial Electronics and Applications (ICIEA '10), pp. 689-694, June 2010.

[41] S. Xu and H. Wu, "The research and analysis of the efficiency of automobile ABS brake based on fuzzy control," in Proceedings of the 2nd International Conference on Consumer Electronics, Communications and Networks (CECNet '12), pp. 697-700, April 2012.

[42] J.-Z. Zhang and H.-T. Zhang, "Vehicle stability sliding mode control based on fuzzy switching gain scheduling," in Proceedings of the International Conference on Measuring Technology and Mechatronics Automation (ICMTMA '10), pp. 1067-1070, March 2010.

[43] Y. Luo, L. Chen, Y. Li, X. Qiu, Y. Bai, and H. Bai, "Reasonable design of the fuzzy controller parameters in the control system with integral element," in Proceedings of the International Conference on Intelligent System Design and Engineering Application (ISDEA '10), pp. 106-110, October 2010.

[44] H. T. Dorrah and W. I. M. Gabr, "New approach for automatic control modeling and analysis using arithmetic and visual fuzzy logic-based representations in fully fuzzy environment," in Proceedings of the IEEE International Conference on Information and Automation (ICIA '10), pp. 605-612, June 2010.

[45] D. Davendra, I. Zelinka, and R. Senkerik, "Chaos driven evolutionary algorithms for the task of PID control," Computers \& Mathematics with Applications, vol. 60, no. 4, pp. 1088-1104, 2010.

[46] J. H. Chen, W. T. Sung, and H. C. Wang, "MOF synthesis heating process control system research," Applied Mechanics and Materials, vol. 418, pp. 112-115, 2013. 


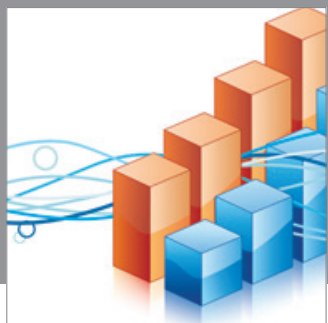

Advances in

Operations Research

mansans

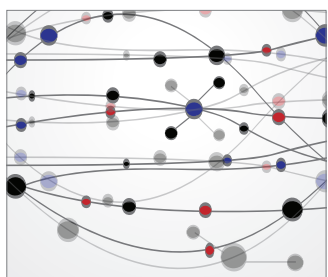

The Scientific World Journal
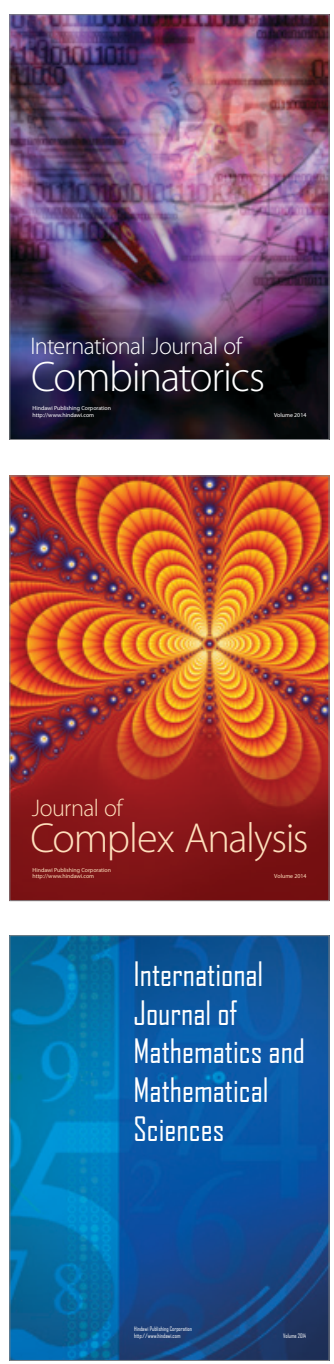
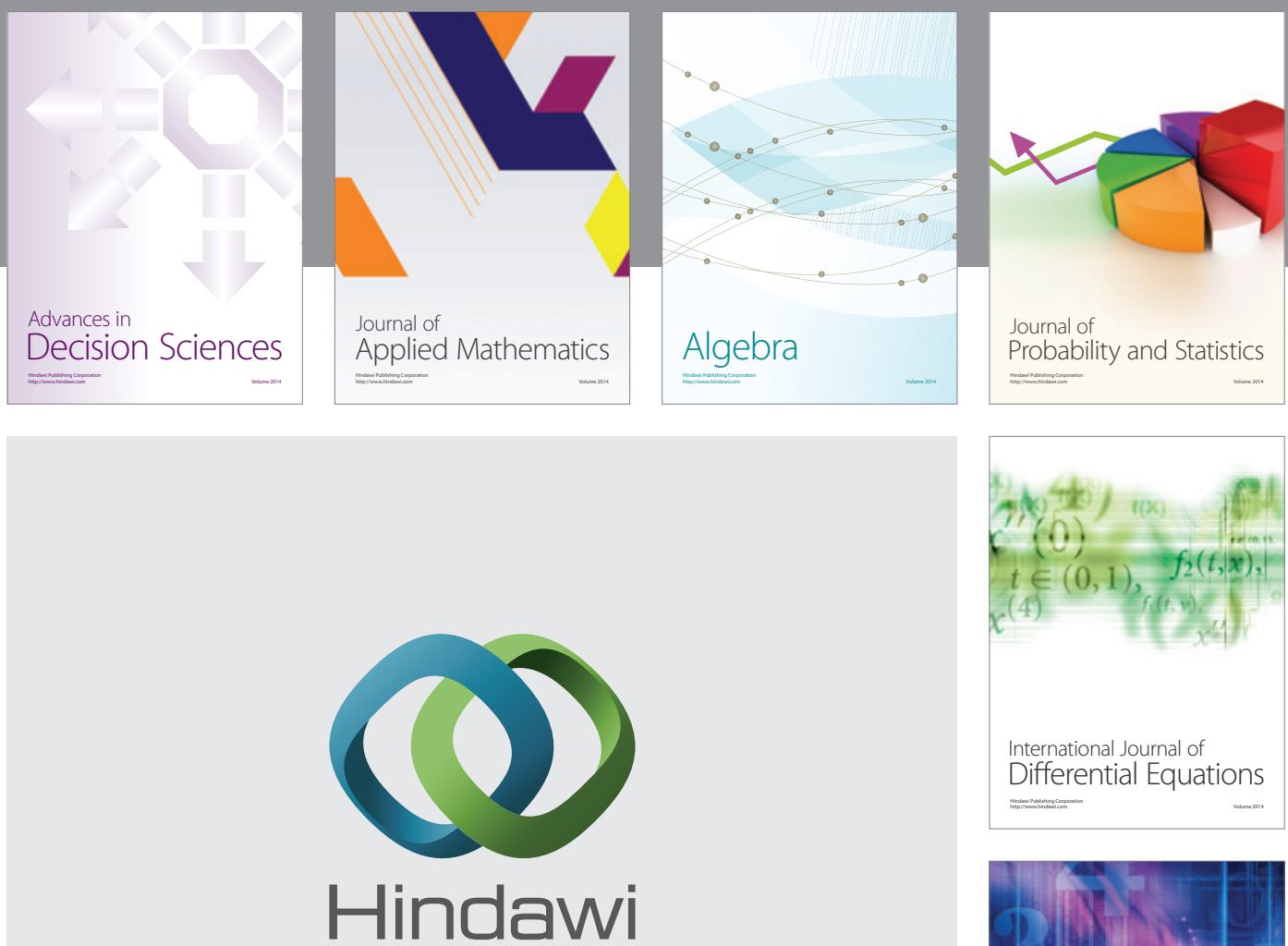

Submit your manuscripts at http://www.hindawi.com
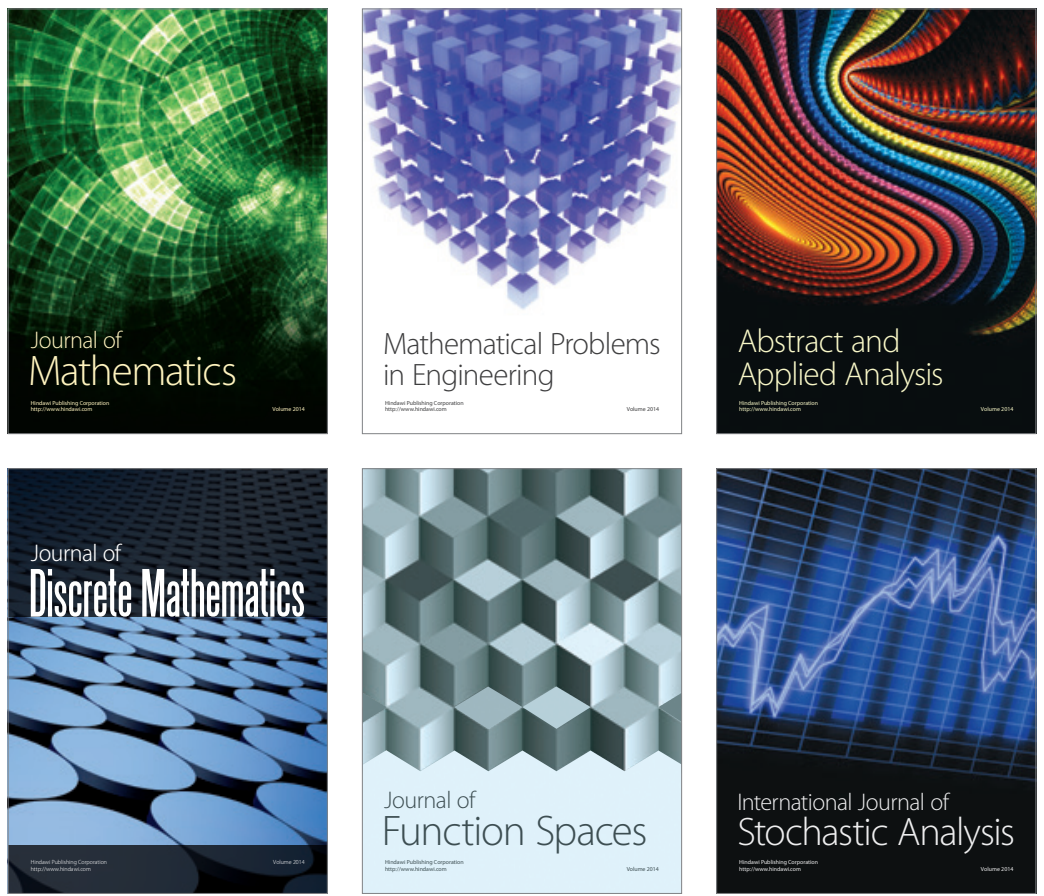

Journal of

Function Spaces

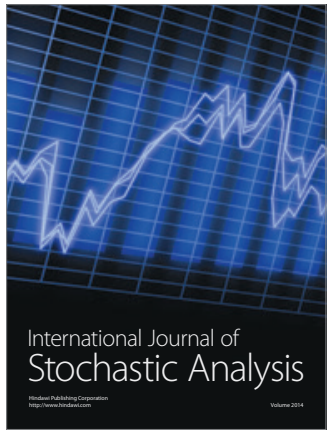

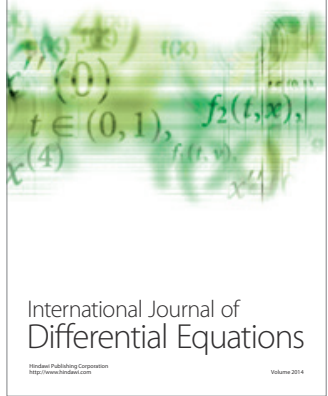
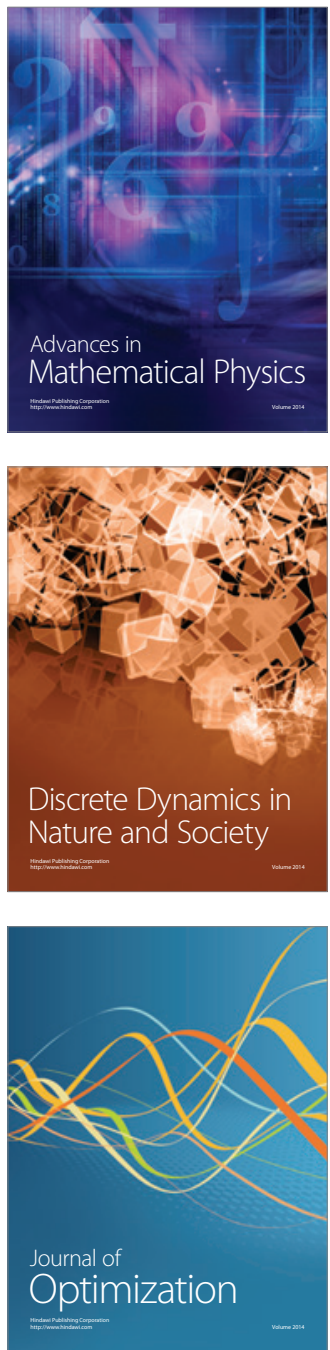